\title{
Corporate and Investment Banking in Italy
}

Cesare Bisoni, Andrea Ferrari, and Alessandro Giovanni Grasso

\subsection{Introduction}

The chapter investigates the way in which the approach taken to corporate banking, and the bank-company relationship, and the strong local roots retained even by the largest groups, all helped to reduce the risk of credit rationing for firms and improved credit risk management on lending to companies in Italy.

Within the bank-company relationship, the second part of the chapter illustrates the nature of corporate and investment banking (CIB) in Italy, describing the way this sector is served by the country's largest banks and outlining possible developments in the light of the recent financial crisis.

\subsection{Lending to companies}

In Italy, banks have always been the main source of external financing for companies, and especially for small and medium-sized enterprises (SMEs), ${ }^{1}$ which are constantly increasing in number due to a general failure to grow in size. The main reasons for this preference for bank finance are the low credit access threshold, the flexibility, and the speed with which loans are issued, the combination with payment services, the easier accessibility and lower cost compared to financing through securities, and the fundamentally "detached" approach of the bank, which does not interfere in the management of companies. This aspect is still very important for family-run companies, which continue to be an essential feature of the Italian industrial scene (Belli and Giordano 2007). 
Small and medium-sized enterprises, with informal governance models, generally use fairly simple forms of financing and in particular are suspicious of external equity. The resulting financial structures are based largely on debt, especially short-term borrowing, often supported by the entrepreneur's personal assets, generating an undesirable confusion and a lack of transparency in creditworthiness assessment. The fragility of firms' financial structures leads to the inappropriate transfer of some of the company risk to the bank, which can only be overcome through closer links to the equity market. Italian firms' financial indebtedness in relation to gross domestic product (GDP) is growing constantly, reaching 84 per cent at the end of 2010; leverage has been over 40 per cent for some time, with a high proportion of short-term bank loans to financial debt (Banca d'Italia 2011a).

Even before the start of the financial crisis, Italian companies showed more obvious signs of weakness than the European average: less ability to generate earnings from the core business, a high level of indebtedness in relation to both sales and equity, and a high incidence of financial costs (De Socio 2010). With the latest developments in the sovereign debt crisis in the Euro Area, and in Italy above all, companies' financial fragility and vulnerability have become even more accentuated.

Table 8.1 highlights the undercapitalisation of small and mediumsized enterprises and reveals that the weight of bank lending within their financial structure is constantly around 25 per cent, even exceeding this value in some years. About three-quarters of debts to banks are short-term, although during 2009 there has been a partial shift towards medium- to long-term loans, generating improvements in financial stability.

Larger companies' lower rates of indebtedness are compensated by higher net capital.

The many studies conducted over time by the Bank of Italy, by many academics, and by various industrialists' associations have underlined the need to improve the bank-firm relationship, viewed as unsatisfactory above all because it is often "transaction" rather than "relationship" based. The relationship is therefore rather short on mutual knowledge and understanding, which partly derives from the sharp separation between bank and company introduced by the 1936 banking law.

Companies' tendency to engage in multibanking, leading to the fragmentation of their relationship with the banks, has always been considered emblematic of this situation. 
Table 8.1 Financing of Italian manufacturing firms, values as percentages of total liabilities

\begin{tabular}{lcccc}
\hline \multicolumn{3}{c}{ Small businesses (revenues lower than €10 million) } \\
\cline { 1 - 3 } & \multicolumn{3}{c}{ Bank loan } \\
\cline { 2 - 4 } Year & Short term & Medium- to long-term & Total & Equity \\
\hline 1999 & 17.66 & 6.68 & 24.34 & 25.75 \\
2000 & 17.75 & 6.88 & 24.63 & 26.47 \\
2001 & 18.02 & 6.71 & 24.73 & 27.45 \\
2002 & 17.82 & 7.05 & 24.87 & 26.67 \\
2003 & 18.43 & 7.53 & 25.96 & 25.58 \\
2004 & 18.07 & 7.89 & 25.96 & 26.02 \\
2005 & 17.86 & 8.38 & 26.24 & 26.65 \\
2006 & 18.40 & 8.56 & 26.96 & 26.05 \\
2007 & 18.89 & 8.85 & 27.74 & 26.00 \\
2008 & 18.09 & 7.98 & 26.07 & 32.43 \\
2009 & 16.02 & 9.32 & 25.34 & 34.19
\end{tabular}

Medium-sized enterprises (revenues between $€ 10-50$ million)

\begin{tabular}{|c|c|c|c|c|}
\hline \multirow[b]{2}{*}{ Year } & \multicolumn{3}{|c|}{ Bank loan } & \multirow[b]{2}{*}{ Equity } \\
\hline & Short term & Medium- to long-term & Total & \\
\hline 1999 & 18.42 & 7.02 & 25.44 & 26.26 \\
\hline 2000 & 18.84 & 6.51 & 25.35 & 26.70 \\
\hline 2001 & 18.81 & 6.53 & 25.34 & 27.52 \\
\hline 2002 & 17.73 & 6.70 & 24.43 & 28.13 \\
\hline 2003 & 17.40 & 7.26 & 24.66 & 29.16 \\
\hline 2004 & 17.08 & 7.38 & 24.46 & 29.14 \\
\hline 2005 & 16.51 & 7.83 & 24.34 & 29.89 \\
\hline 2006 & 16.69 & 8.04 & 24.73 & 29.29 \\
\hline 2007 & 17.81 & 8.32 & 26.13 & 29.02 \\
\hline 2008 & 17.49 & 7.88 & 25.37 & 33.03 \\
\hline 2009 & 15.65 & 8.62 & 24.27 & 36.11 \\
\hline \multicolumn{5}{|c|}{ Large corporate banks (revenues more than $€ 50$ million) } \\
\hline & \multicolumn{3}{|c|}{ Bank loan } & \\
\hline Year & Short term & Medium- to long-term & Total & Equity \\
\hline 1999 & 12.38 & 7.19 & 19.57 & 29.84 \\
\hline 2000 & 12.26 & 6.59 & 18.85 & 31.07 \\
\hline 2001 & 12.43 & 7.18 & 19.61 & 30.38 \\
\hline 2002 & 11.02 & 6.58 & 17.60 & 31.22 \\
\hline 2003 & 10.24 & 6.86 & 17.10 & 30.92 \\
\hline 2004 & 9.17 & 6.03 & 15.20 & 32.71 \\
\hline 2005 & 8.67 & 6.24 & 14.91 & 32.96 \\
\hline 2006 & 9.11 & 6.09 & 15.20 & 33.47 \\
\hline 2007 & 9.17 & 6.68 & 15.85 & 33.37 \\
\hline 2008 & 9.93 & 6.37 & 16.30 & 34.22 \\
\hline 2009 & 8.34 & 6.86 & 15.20 & 34.33 \\
\hline
\end{tabular}

Source: Processing of BACH - Bank for the Accounts of Companies Harmonized. 


\subsection{The practice of multibanking}

Multibanking has been encouraged by wide variety of factors, including

- from the banks' side: by the lending timespan specialisation imposed by the 1936 banking law, which basically remained in force until $1993 ;^{2}$ by the constraints with regard to risk concentration; by the small size of most of the banks, meaning that they were unable to completely satisfy the largest firms' financial needs; and by the low margins on loans, which led to a preference for insurance-based risk management;

- from the companies' side: by the positive attitude to indebtedness encouraged by more favourable tax law and entrepreneurs/shareholders' strong propensity for a lack of transparency in their reporting, partly for fiscal reasons.

Pelliccioni and Torluccio (2007) attempted to identify the main reasons for the popularity of multibanking. Their study reveals that the number of banking relationships increases in direct proportion to company size, leverage, and the need for financial instruments other than those traditionally offered by banks. Multibanking decreases in step with lack of clarity in investments in research \& development and investment in tangible fixed assets, and when economic and financial conditions improve.

Both banks and companies considered the practice of multibanking to be beneficial. From the bank's point of view, multibanking reduces credit risk by sharing it across a large number of institutions, with a consequent limitation of the costs of information and creditworthiness assessment (often problematic due to the lack of transparency in information), and makes it possible to stop financing the company further in the event that danger signals are noted, and to cancel the credit line if necessary. Companies view favourably the fact that they can trade their supplier banks off against each other and thus save on the cost of money, avoid revealing their real economic and financial situation to any of the banks, and protect themselves against the sudden cancellation of credit lines, which may occur, especially at times of financial difficulty.

In reality, these benefits are more apparent than real. The fragmentation of credit risk due to the spread of lending across a number of banks, and the strong weight assigned to collateral as a parameter for assessing the company's solvency, discourage banks from acquiring 
significant information about companies, weakening their role as selectors of investment projects. The consequence may be that they lose a sense of responsibility, and tend to follow, as one author has aptly put it, a sort of "herd instinct" (Ciocca 1991). These types of inefficiency in the allocation of lending may be even more detrimental for the small and medium-sized enterprises with the best prospects for growth and profitability. Furthermore, an approach based on limited mutual knowledge leads the bank to underestimate overall credit risk and to apply a higher spread across-the-board to cover higher losses on loans, not to perform creditworthiness assessment with the necessary professionalism and expertise, and thus to require higher collateral, behaving in the way companies have always criticised; it also prevents banks from providing companies with useful advice and recommendations.

For the company, multibanking implies sacrificing the opportunity of across-the-board financial advice from a single source and losing the chance of reducing overall costs by integrating the various services used. Moreover, empirical research has demonstrated that firms are less likely to suffer credit constraints when they do business with only a few banks (Guelpa and Tirri 2004).

Therefore, in general terms, the practice of multibanking creates a weak relationship between the bank and the firm, which, as we have already seen, tends to be transaction-based (Ruozi and Zara 2001) and multibanking discourages the establishment of relationships that last over time. A respected leading figure in the Bank of Italy summed up the problem in a nutshell years ago: "Firms rely on banks both too much and not enough" (Padoa-Schioppa 1995).

The multibanking approach is still very widespread, although there has been a gradual reduction in its prevalence in the last few years, hand in hand with an increase in the proportion of lending provided by the company's chief bank.

Table 8.2 reveals that the average number of banks per borrower company fell between 1998 and 2010 from 2.96 to 2.51 . The data by size category of the total credit line granted reveals that this reduction, which has accelerated from 2006, is particularly noticeable for companies in the largest size classes, although they still do business with a large number of banks. This is no surprise, given that even companies with total access to credit of less than $€ 1$ million, and thus of small size, work with nearly three banks from 2005. Basically, progress in the reduction of the number of banks is in the right direction but is rather slow; there is still a long way to go towards the model in which one main bank satisfies the majority of the company's financial needs. 


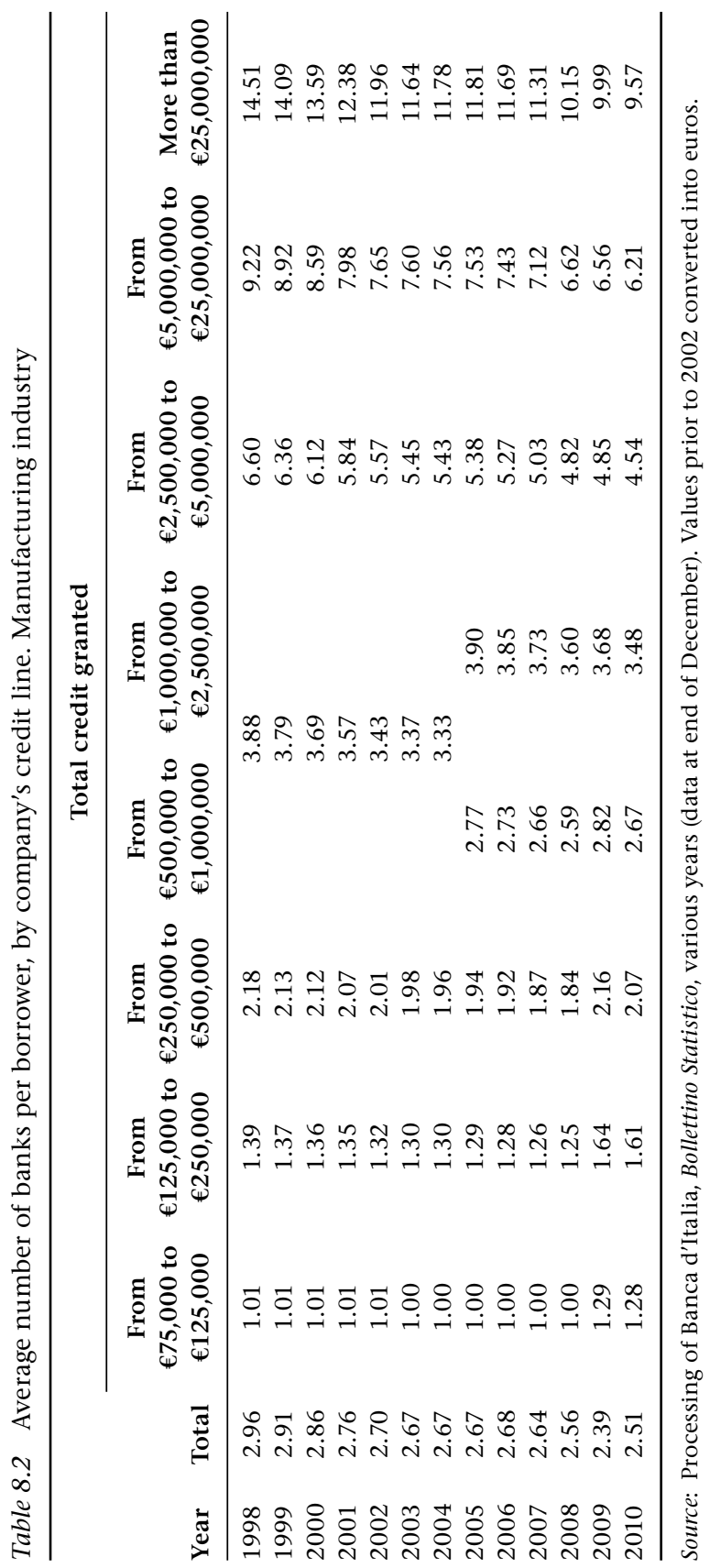


Table 8.3 shows that this is already the case for the smallest firms, while for those with access to credit of more than $€ 1$ million, the chief bank covers less than 60 per cent of their borrowing needs; this figure falls to around 40 and 30 per cent for companies in the two largest size categories. In any case, predominance from the point of view of the credit line granted is not in itself symptomatic of a satisfactory preferential relationship.

Therefore, on average Italian companies maintain relations with more banks, with a smaller proportion of their lending from their chief bank, than companies in other countries.

The reduction in multibanking that has occurred cannot be imputed only to the consolidation process that has taken place in the banking industry. It is partly due to the process of branch liberalisation. The reduction in the total number of banks has been accompanied by a significant increase in the average number of banks operating in the local markets (Tarantola 2007). This increase has occurred above all in the markets where economic activity is most intense, and thus where the needs for financing to cover investment projects mainly arise. Therefore, the trend away from multibanking can also be interpreted as a growing awareness of the costs and risks of this practice (Cesarini 2003).

The weakness of bank-firm relationships based on multibanking is also confirmed by studies performed to examine its effects on credit availability in the specific context of the financial crisis. In particular, empirical findings reveal that "Firms which borrow from a larger number of banks experience lower credit growth, while firms with more concentrated credit experience higher credit growth." (De Mitri et al. 2010).

Moreover, companies that borrow from many banks are also more likely to be credit-constrained. On the other hand, more concentrated lending with the main bank, with the latter providing a high proportion of lending, reduces the probability of being asked to cut credit. The effects of the stability of the banking relationship are clear, since the relationship only becomes significant if it is of sufficiently long duration (De Mitri et al. 2010).

With the start of the crisis, there has been a great deal of discussion as to the degree of credit constraint firms may have suffered from, and this has highlighted a controversial aspect of the bank-company relationship. More rigid lending criteria and an increase in the number of firms having difficulty in accessing bank loans are typical of recessions and arise from a deterioration in the quality of loans. However, since the crisis had a number of causes, it is not possible to establish whether 


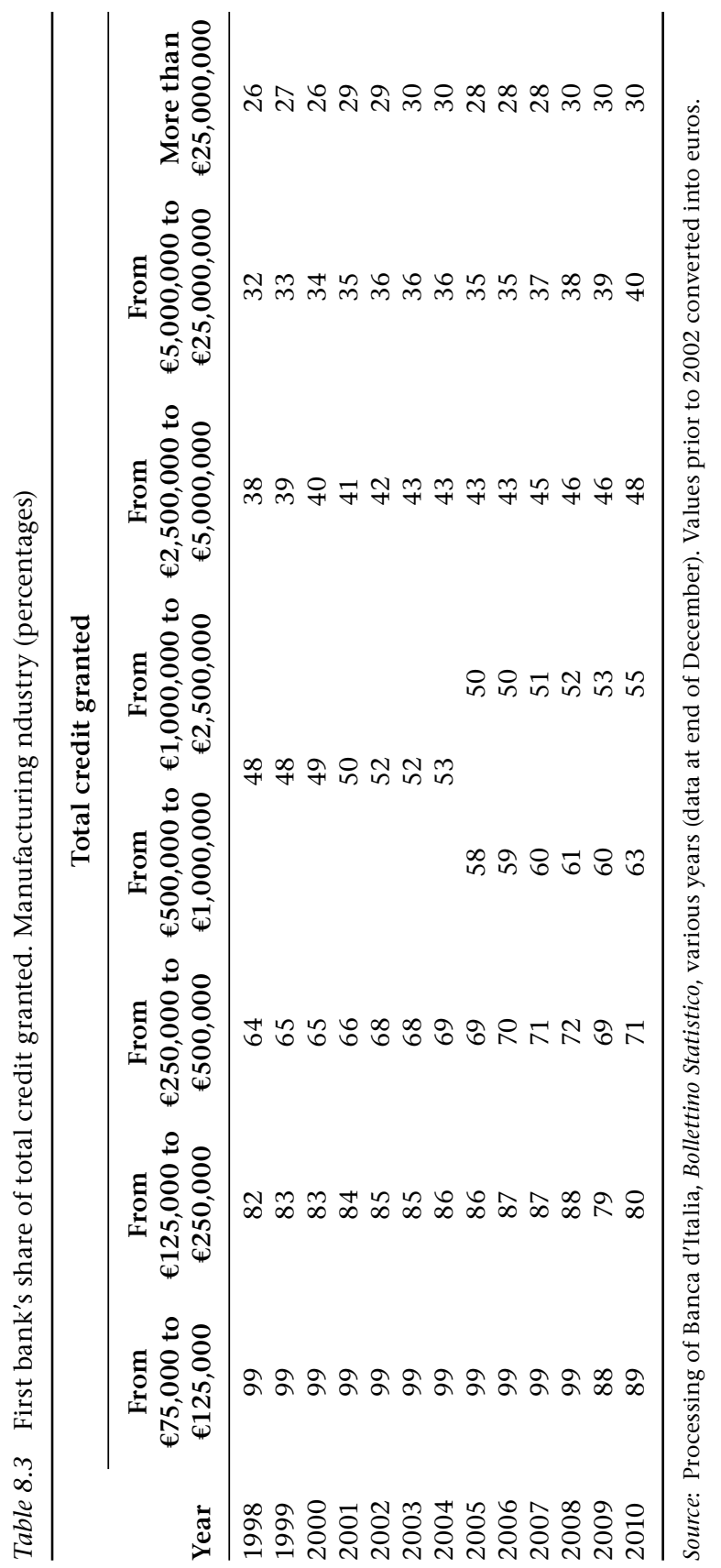


and to what extent the credit squeeze that undoubtedly occurred during the period was due to demand-side factors or to a supply-side shortage. Similarly, it is not possible to state beyond doubt whether the reduction in the availability of loans was due, even partially, to decisions and constraints within the banking system. During 2011, the raising of the bar noted in the criteria for lending to companies appears to be directly linked to banks' liquidity situation and funding difficulties, as a consequence of the tensions surrounding Italy's sovereign debt.

However, with regard to the existence and extent of constraints on lending to companies, the findings of questionnaire surveys conducted regularly by Osservatorio UniCredit have been available for some time, and thus also cover periods prior to the crisis. ${ }^{3}$ Their results provide information about small firms' perception of the degree of rationing suffered before and after the peak of the crisis. A comparison between the replies provided during the two years covered by the survey, 2008 and 2009, indicates that, while there was a clear increase (from 26.7 per cent to 44.4 per cent) in the number of firms that would have liked to obtain more loans (weak rationing), the number that would have been unable to obtain loans even if they had been prepared to pay a higher interest rate (strong rationing) was 5.0 per cent for 2008 and 7.6 per cent for 2009. The data indicate only a fairly limited rise in the level of rationing. If the comparison is extended to the pre-crisis period, the proportion of companies that feel credit-constrained, although significant, ${ }^{4}$ is sharply below the level for 2008 and 2009.

With the onset of the crisis, there was also a marked deterioration in the quality of the loans granted. Bad debts (loans granted to borrowers who are insolvent or are in basically equivalent situations, regardless of collateral), which accounted for 3.11 per cent of the total loans granted in December 2007, had risen to 5.40 per cent in March 2012.

If measured on the basis of impaired loans, meaning not only bad debts but also loans to subjects in temporary financial difficulty, ${ }^{5}$ the quality of loans is very low, and is constantly deteriorating. Compared to December 2008, the number of impaired loans as of March 2012 (Banca d'Italia, Bollettino statistico, various years) had doubled, from 5.11 per cent to 11.62 per cent of total loans.

\subsection{The process of change within the banking system}

During the last twenty years, especially due to the introduction of the Consolidated Law on Banking of 1993, the Italian banking system has undergone deep-seated change involving the main factors 
influencing the bank-firm relationship, which has led banks to rethink their approach in this area. The following are particularly significant:

- consolidation within the banking system, which has involved a large number of banks of all sizes and has caused major changes in market shares, also benefiting the "independent" banks, i.e., mutual banks and banks that do not belong to groups (Tarantola 2008);

- the inclusion of efficiency amongst the aims of supervisory policy, which has generated changes in banks' culture and governance;

- the despecialisation of intermediaries in terms of areas of business and lending time-scales, the introduction of the universal bank and the consequent opening-out of operating possibilities;

- the growth of competition and the increasing specialisation of the financial system, which have led banks to prioritise "relationships" and thus to introduce loyalty-creation strategies based on the delivery of customised services rather than strategies for increasing client numbers through price alone;

- the evolution of banks' organisational models, partly as a result of the many M\&A operations, which has increased the capability for meeting firms' needs by means of a broad, complete product offering.

The changes outlined above have created favourable conditions for the improvement of the quality of the bank-firm relationship. In fact:

- Banks are free to target their policies, and, although with variations within the system, they have developed an entrepreneurial approach to the market, offering a full, diversified service. Therefore, the relationship with firms is able to become deeper and more complex and can be fulfilled through new operating procedures. Basically, the conventional lending function can now form part of a complete, integrated assistance and advisory service.

- Firms are showing signs of paying more and more attention to their relationships with banks and the opportunities offered by the financial markets. They tend to classify banks' offerings on the basis of their ability to satisfy specific needs that arise, and they appear to be tending to rationalise the number of their banking relationships, reducing their degree of multibanking, the supposed benefits of which now seem to be less clear. Many well-run companies have already introduced measures to restructure their relationships with the banking system and to attempt to established closer relationships with individual banks. 


\subsection{From the Consolidated Law on Banking to Basel II: Implications for the bank-company relationship}

In Italy, there has always been a tight bond between small and mediumsized enterprises and the local banks, whose main strength lies in their local roots, which allow them to maintain close relationships with the local economy and community; the absence of geographical separation between the bank's top management and the clientele; and their greater willingness to support firms in hard economic times.

These banks have always placed their dealings with small and medium-sized enterprises on a relational footing. This is due to the characteristics of firms of this kind, in terms of both ownership structure and financial management, since their level of capitalisation is low and the processes by which they analyse and plan their financial needs tend to be rudimentary.

If this model of relationship, which includes the positive features mentioned above, is not to produce adverse effects, the bank must retain its own independent capacity to assess a firm's creditworthiness, ensuring that the personal acquaintanceship with the firm's owner that has developed and has been consolidated over time does not lead to decisions inconsistent with the degree of risk considered acceptable, especially in situations where the company's continuity and survival may depend on increased access to credit. In this area, organisational decisions and considerations with regard to the degree of mobility of branch managers are significant; keeping staff in one place for a long time aids the acquisition of soft information, but on the other it may lead to information asymmetries with the bank's central management.

The basic aim of Basel II was to foster a culture of risk awareness amongst banks and to create a direct link between levels of capitalisation and the degree of risk actually undertaken, increasing management's involvement and sense of responsibility in this area (De Laurentis and Caselli 2004). For banks capable of implementing proper, effective risk management methods, this should lead to a reduction in costs, enabling banks to charge lower prices to their best corporate customers, and in particular to those capable of providing, in a transparent, standardised form, current and budget information useful for the accurate assessment of their economic and financial stability and thus of their creditworthiness. In any case it is possible to establish a clearer link than in the past between the price of loans and the risk undertaken by the bank, also benefiting small and medium-sized enterprises, often penalised by their lack of bargaining power (Tarantola 2008). 
Basel II encourages banks to introduce more structured lending processes, greater standardisation and formalisation of information, and a different sequence of phases in their creditworthiness assessment procedures.

The problems lie, on the one hand, in smaller-sized firms' inability and/or unwillingness to provide the bank with correct, transparent information in a standardised form, often due to their lack of a properly developed financial function, and on the other, in the difficulty of incorporating soft information, and subjective information above all, in models. Soft information is the type most subject to information asymmetries and is the most difficult type for the relationship's manager to assess and interpret, but it is often the most crucial form of information because it reflects the most important, distinctive aspects of the company's business.

Assessing the creditworthiness of small and medium-sized enterprises is problematical as a result of their undercapitalisation, poor returns, and consequent low investment capabilities; the use of the entrepreneur's own assets as collateral is often fundamental to the granting of a loan. In cases of this kind, qualitative information is of major importance (Mieli 2009).

Apart from causing the loss of valuable information available to the client manager (often the branch manager), the problems of giving due weight to the soft information in the evaluatuion process may result in significant changes in bank-firm relationship, including on the availability and cost of credit, something that like many representatives of the business community complain. It is worth focusing attention on this topic because it may have negative consequences for the relationship between the bank and the customer firm and its potential development; in general terms, it may delay or even prevent the transition from the transaction to the relationship banking model (Cosma 2002).

The use of soft information for the purposes of credit risk assessment is easier where the distance between the bank's decision-making centres and the firm's geographical location is small, because an appreciation of specific features of the local economic and sociocultural context is fundamental for the correct interpretation and exploitation of information of this kind (Cosma et al. 2003). This points to a potential competitive advantage for local banks over large intermediaries, especially when the organisational model chosen by the latter is divisional by areas of business, which may cause fragmentation of the relationship with the customer-enterpreneur. This may explain the strategies adopted by some large banks, and especially those created by merger processes 
involving local banks, which have reviewed past decisions with regard to the localisation of lending decision-making centres and shortened the decision-making process (Albareto et al. 2008), handing a major role back to outlying offices, with the added advantage of reducing information transfer costs and the length of time needed to respond to customers' requests. These decisions have also been triggered by the erosion of the shares of the small and medium-sized enterprise market segment suffered by the large banks during the last few years, ${ }^{6}$ which might be explained by these companies' preference for the relational approach (Bonaccorsi di Patti et al. 2005).

The negative impact on relations with small and medium-sized enterprises, especially with regard to the proportion of lending allocated to them, was less in cases in which growth was achieved during acquisition processes that kept the local target bank in operation, meaning that the benefits of geographical roots, in information and other terms, were not lost (Beretta and Del Prete 2007). It should also be mentioned that thanks to the development of information technology (IT), it is now possible to process a large proportion of soft information, reducing the large banks' competitive disadvantage in relations with small and medium-sized enterprises compared to their smaller counterparts.

A sample survey conducted by the Bank of Italy and involving more than 300 banks reports an acceleration in the introduction of quantitative models for the assessment of creditworthiness, even for smaller firms, in smaller-sized banks; in 2006 about 60 per cent of these banks applied the new methods to their lending decisions and to the calculation of credit lines and collateral requirements. However, it should be underlined that only 18 per cent of the banks in the sample considered these tools of key importance, and virtually the only factors considered were financial statement data and current borrower status (Albareto et al. 2008), confirming the difficulty of completely including soft information and the amount of work still to be done before it becomes possible to assign the right weight to qualitative information which, if overlooked, could lead to the rationing of credit or unnecessary increases in the costs applied (Tarantola 2007).

Qualitative information can be acquired and used more easily and with less complexity by smaller banks in view of their nearness to the customer. Under Basel II, the clientele of small and medium-sized enterprises enjoy favourable treatment: for banks that use internal ratings, loans granted to them require capital coverage up to 50 per cent lower than those granted to large corporations, which are considered more exposed to economic cycle risks (Mieli 2009). 
In spite of this, with the onset of the financial crisis firms have faced tougher lending terms, and in their perception the banks' changed behaviour is due not only to the different economic context but also to the application of the Basel II rules. Although really the outcome of the increased credit risk, difficulties in accessing credit have been attributed to the new rules.

Banks appear to make little use of the override mechanism envisaged by the regulations to ensure that rating systems are flexible and up to date, mainly because of risk managers' unwillingness to take responsibility for using it. This instrument, where the necessary conditions are met, allows the bank to make effective use of the information available to it and increase its lending efficiency (Mieli 2009).

De Angeli et al. (2007) reveal that small enterprises believe that they have not received sufficient information about the rating process and its underlying principles, and thus about the factors that affect the rating assigned; in their view, this prevents them from taking action to ensure that they are assessed more accurately. Moreover, there is still a widespread conviction that the banks assign great importance to economic and financial information in their lending decisions, and do not pay due attention to qualitative information. Last but not least, although they realise there are benefits in establishing closer relations with one or just a few banks, many small firms hesitate to reduce their number of banking relationships because they are afraid that this may lead to a reduction in the financial resources to which they have access, and they still believe it is advantageous to trade banks off against each other. This may also be due to the belief that obtaining bank loans has become more difficult as a consequence of the transition to Basel II.

\subsection{Towards a new bank-firm relationship}

If the bank-firm relationship is to be improved, banks need to continue resolutely with the changes implemented in the last few years, above all by extending their knowledge of the firm and the sector in which it works.

This implies making an assessment of the firm that includes an analysis of its competitive position in its sector, verification that the critical factors for success are available, forecasting the cash flows associated with investment projects, and identifying the characteristics of financial needs, essential for choosing the appropriate mix of financing.

An approach of this kind conflicts with the practice of multibanking but is compatible with the use of a single bank of reference, which 
knows the company and is capable of supplying a broad range of financial services, aiming to achieve a return not on the individual operation but on the relationship overall.

The bank must have suitable technologies and professional competences, together with an organisational structure that facilitates contact with the company, the acquisition of the necessary information on investment projects and on the business as a whole, and correct, swift lending decision-making. The principles on which the bank organises the division and coordination of work in this sector affects the quality of the credit-offering process and its ability to select and support deserving projects.

The degree of development and formalisation of the financial function has a major impact on firms' ability to communicate their objectives and financial needs to the bank and helps to improve the quality of the relationship (Ruozi and Zara 2001).

Another important factor is the bank's ability to support the company's growth by organising integrated financial service packages and offering professional advisory services that assist the firm in making fully informed decisions, especially with regard to harmonising the characteristics of financial needs and the instruments used to cover them, in line with strategic objectives. This aspect, which still appears to receive too little attention (Bentivogli et al. 2007; De Angeli et al. 2007), is particularly problematical for small banks, which have traditionally concentrated on lending but may lose their role of main bank if they are unable to adapt their offering to the changed needs of the core clientele. The problem can only be partially resolved through the development within groups or categories of banks of forms of collaboration with larger-sized intermediaries, from which the products required by the clientele can be purchased.

Last but not least, banks can provide a major contribution to strengthening the financial structures of even small-sized firms with growth potential, by assisting their entry onto the equity market.

Venture capital and private equity can also be useful tools for diversifying SMEs' sourcing of finance, with the aim of maintaining leverage at an acceptable level in terms of risk and the cost of finance. Moreover, these forms of investment may enable the firm to grow its management expertise, because the financing project generally involves involvement in the management of the firm, which may be particularly useful in growth phases, and may help to reduce information asymmetries in relation to the market. The underdeveloped state of these markets not only constitutes a gap in the Italian financial system, but also discourages 
the stock market listing of companies, already viewed with suspicion by many entrepreneurs, who are afraid of losing control of their businesses. Moreover listing is considered problematic due to the costs and the organisational and corporate structural changes required by the current regulations. Companies' failure to list on the stock exchange reduces the ability of venture capital and private equity operators to make funding available, which discourages investment.

In addition, banks' support in obtaining funds from equity markets not only assists companies' growth, but also extends the intermediary's knowledge of its client, the importance of which has already been underlined above.

However, for the banking system to make the necessary contribution to strengthening firms' financial structures, the latter must become more willing to accept the bank as a partner, interested in both the success of business and in the inclusion of new shareholders when it becomes necessary to increase its risk capital, overcoming the typical fears of Italian entrepreneurs. It is also essential for the bank not to exploit the dominant position acquired in relation to the firm solely to its own advantage, and to reinforce the relationship and the loyalty of the customer firm by its behaviour.

The above comments clearly reveal that, in spite of the progress made in recent years, there is still room for improvement in the bank-firm relationship, which must constantly adapt to changes in the factors that influence it.

First and foremost, both parties must make a great effort to change their mindsets, essential for the transition from what is often an antagonistic relationship to one of open collaboration based on mutual trust, which may allow the bank to support good business ventures even in unfavourable economic contexts. This process is definitely under way, and it has recently accelerated, but it is important to be aware that there are wide variations, especially between different parts of the country, and rapid progress is required.

An improvement of the professional competences of the people working within both banks and firms is also necessary; the lion's share of responsibility in this area lies with the banks, in view of their tradition and of the experience they have acquired over the years. What is required is progress in the direction many banks have been following for some time, with an increase of the number of people, within their organisations and above all in the points of contact with the clientele of staff, who are capable of managing highly specialised demand with a strong degree of personalisation. 
Finally, firms, and especially small and medium-sized enterprises, must equip themselves to extend their knowledge of their economic and financial situation and its expected evolution. This would benefit their management and would enable them to provide the bank with the information needed for an objective reliable evaluation of their creditworthiness and for monitoring of the relationship on a regular, standardized basis. Furthermore, firms' adoption of formal governance and control models would also win them easier access to external finance, essential for the support of growth processes and for reducing their capital costs.

In conclusion, greater cooperation between the two sides is required, based on transparency; willingness on the part of firms to provide banks with the quantitative and qualitative information necessary for familiarity with their situation and characteristics; the full, correct use of this information by banks in the creditworthiness assessment procedure and in the choice of financing services and their pricing; and a durable relationship.

\subsection{The development of the corporate and investment banking business}

The positive development of the bank-firm relationship involves the evolution not only of corporate lending, but also of corporate and investment banking services.

The term "investment banking" normally refers to a combination of products and services designed to satisfy a wide range of complex financial needs, which are different from the ordinary financing requirements of the firm's business operations.

The corporate and investment banking services area may offer concrete solutions to a variety of requirements. Financing for growth strategies that represent a major break with the past; access to the equity market; management of generational changeovers; optimisation of debt structure; reconfiguration of the core business; and plans for ownership restructuring or the entry of new financial investors are all examples. These services satisfy needs shared by all firms, needs whose intensity and nature vary depending on the firms' size, sector of business, life cycle phase, ownership structure, and governance model.

Moreover, the complexity of the needs served means that the solutions offered by intermediaries must be equally complex in terms of know-how, production processes, technical-contractual profiles, and pricing models. Therefore, the survey of corporate and investment 
services gives separate consideration to the various areas of business: capital markets, corporate finance, merchant banking, project finance, asset management, and risk management. It is not necessarily the case that all these areas must or can be effectively covered within the organisation of a single financial intermediary (Capizzi 2007).

The 1990s saw the introduction of processes intended to extend the range of services offered to firms. Interest in this business sector developed mainly within the banking system and to a much lesser extent amongst specialist and specific financial service companies. This is due above all to the process of diversification of areas of business that affected banks during this period and the largely marginal role of specialist financial intermediaries in the Italian context. In contrast to the situation in the United States and the United Kingdom, banks in Italy became the focal point for the development of CIB services.

The characteristics of the financial system, focused more on intermediaries than on markets, meant that in Italy CIB was on a smaller scale than in other financial contexts such as the United States, the United Kingdom, France, and Germany. Some figures will provide a clearer understanding of the context. At the end of 2010, Italy had only 332 companies listed on the stock exchange, compared to 639 in France, 765 in Germany, and 2,603 in the United Kingdom. In terms of breakdown by industry, two-thirds of the value of the Italian stock market were represented by just 10 corporations, operating in the financial, oil and public utilities industries, and there were very few listed firms in the most high-tech, innovative sectors. Considering the 10 initial public offerings and 18 rights issues during the year, in 2010 the equity segment of the capital market attracted investments of $€ 10$ billion, 25 per cent of which referred to just one operation. The most important part of the entire Italian capital market is thus the bond segment, with €713 billion. The corporate sector accounts for just 4 per cent of this total, and here again it is extremely concentrated, with 50 per cent of the funds invested received by just four issuers. Therefore, in general the corporate segment features low volumes and very few issuers, reflecting the fact that only a small number of large-sized firms use the financial markets as a source of capital.

The nature of the entrepreneurial fabric and the financial system thus underlie the characteristics of the supply and demand for corporate finance and investment banking services in Italy. The distinctive features of Italian industry are the large number of small-sized enterprises (Eurostat 2011), the centrality of family-based capitalism (Amatori et al. 2011), and the predominance of owner-management (Brandolini and 
Bugamelli 2009), which leads to a lack of distinction between the assets of the family and those of the firm, problematical when complex economic variables have to be managed.

Firms' size and governance models influence their financial strategies. Several studies of the Italian situation (Caselli 2001; Cenni 2006; Caselli and Gatti 2005; Caruso and Palmucci 2008) have demonstrated a high degree of correlation between the services requested and corporate dimensions. The range of financing services used by small firms in particular is very limited, and as the first section of this chapter makes clear, bank lending is the method of choice. In line with the pecking order theory, Italian firms' financial preferences start with the least complex and expensive option in terms of organisation and relationships, and they rarely make use of sources of financing (whether risk capital or lending) requiring greater openness to the outside in terms of information.

The demand for CIB can be clearly subdivided by firm size. SMEs are apparently largely excluded from access to the capital markets, in spite of the launch of segments specifically intended for them, such as the Alternative Investment Market (AIM), both for cultural reasons and due to volume factors. They are therefore more interested in advisory and merchant banking than in underwriting services. On the other hand, large corporations are potentially interested in the entire range of CIB products and services.

As well as demand, the supply of corporate and investment banking services is also affected by the regulatory framework, which affects operators' strategic choices. This market has developed in Italy more recently than in other contexts, and it is smaller due to the regulatory framework of the financial sector and the state's involvement in the economy, arising from the financial crisis of the 1930s. Although it did not create legal impediments to the securities industry, the inspiring principle of Italy's 1936 banking law, which remained in force for more than half a century, was to prevent commercial banks from making direct investments in corporate equity. The experience of the crisis that hit the universal banks in the 1930s led to the fear that any long-term financial support, whether in the form of lending or equity investments, might make commercial banks' solvency too closely dependent on that of its customer corporations. The consequent strict distinction in operating time-scales and types of business between banks and special credit institutions survived until the 1990s.

It was not until the implementation of European Union (EU) legislation that a number of independent investment banks and the 
commercial banks started to extend their operations to include the provision of financial assistance to firms. The period from the 1990s onwards has seen a number of changes with regard to investment banking and private equity on the Italian market; in particular, commercial banks have shown a decided interest in the investment banking sector. This has led to acquisitions of investment banks that originated from strategic motives regarding the cross-selling of services and the internalisation of higher-margin earnings. Acquisitions have involved both investment banks and specialist merchant banks. ${ }^{7}$ This process was encouraged by the reduction in margins on the traditional lending business, as well as by the new regulatory approach.

Another factor that helps to explain firms' preference for lending as a source of finance derives from fiscal regulations. In Italy, this has historically not been neutral in relation to corporate finance strategies, favouring the financing of investments through indebtedness over the use of equity. The interest paid on loans can be deducted from the company's taxable income, while the financial costs of risk capital cannot; moreover, returns on risk capital are subject to higher taxation than those on capital used for lending. This fiscal favouritism has been reduced but not eliminated over the years.

\subsection{The structure of the supply of corporate and investment banking services}

In Italy, the corporate and investment banking services market is occupied by domestic and foreign operators, with a variety of organisational types: the investment banking units of the large banking groups, the few remaining pure investment banks, ${ }^{8}$ and the many financial advisory firms.

The foreign operators ${ }^{9}$ cover large geographical areas, offer a wide variety of products, and serve a large number of types of customer. Their main clientele consists of large or medium-large corporations, since the resources available for the Italian market and the budget targets set by central managements make the middle market less profitable. Some operations are handled directly by teams working in Italy, while particularly complex transactions requiring large amounts of funding are referred to central offices. ${ }^{10}$

Domestic operators subdivide into two categories: banking and non-banking. The banking operators include international groups: UniCredit and Intesa Sanpaolo, which at the end of 2010 held 32.9 per cent of the system's assets, (Banca d'Italia 2011a) and Mediobanca. 
From the operating point of view, UniCredit and Intesa Sanpaolo can be defined as commercial banks that engage in investment banking; Mediobanca, the intermediary closest to the United States' or United Kingdom's investment bank model, is historically the most important institution on the Italian corporate and investment banking scene, and since 2003 it has followed a policy that has made it into an investment bank that engages in commercial banking business. These organisations hold large shares of the domestic market and offer a very wide variety of services that place them in direct competition with foreign banks.

There are also banking groups operating only at the domestic and local level, such as Monte dei Paschi di Siena, Banco Popolare, and UBI Banca, with 18.9 per cent of the system's assets. These three institutions offer products comparable with those of the main players; smaller banks may even not offer products in this category at all, by reason of the type of clientele served.

As well as the banks, the sector is also served by a wide variety of other organisations, such as professional firms, financial intermediaries, and securities firms, which all together produce the usual assortment of CIB services.

An examination of the business model of the top five banking groups listed above and Mediobanca highlights some significant factors: the organisational model adopted, the type of service offered, the clientele segmentation, the depth and breadth of the service, and the degree of internationalisation.

An analysis of the business model of the main Italian operators, based on the model of the multifunctional group that provides investment banking functions within its organisation, reveals a number of major differences compared to the wholesale/broker-dealer model generally found in the United States and United Kingdom. The latter model has a number of key features (Scardovi 2009): a high level of financial leverage; widespread use of maturity transformation, leading to a rise in liquidity risk if the rate of portfolio rotation slows due to unfavourable conditions on the financial markets; use of the financial markets as the main source of funding; and a cyclic trend in asset management and proprietary trading business, with an absence of profit stabilisation. As a result of the liquidity crisis associated with the recent financial crisis, the panorama of big investment banks has undergone profound changes since 2007. ${ }^{11}$

Most Italian operators, including the largest players, adopted an approach that integrates their lending, advisory, and capital market 
activities. Wholesale lending is financed with the deposits of the retail clientele, a source of funding that is less expensive and more stable for the borrower (Banca d'Italia 2011a) and thus allows the relative degree of liquidity risk to be reduced for a given level of investments. The level of leverage is generally lower than that of international players, even in the case of Mediobanca. ${ }^{12}$

Here it is of interest to trace the story of Mediobanca, which was founded just after the Second World War to serve the medium-term needs of industrial enterprises and to establish a direct relationship between savers and the finance needed to restore companies' production operations. It eventually became Italy's leading investment bank. Since 2003, Mediobanca has also diversified its operations towards retail banking, especially the acquisition of deposits from savers, to expand its access to "quality" sources of funding that are less expensive and considered more stable.

From the institutional point of view, the way banks choose to locate the lines of business that make up the corporate and investment areas within their organisations varies. Banks' organisational strategies favour divisional or group models, with a greater (divisional) or lesser(group) degree of centralisation of the structure respectively. UniCredit and Intesa Sanpaolo are divisionalised groups, while Monte dei Paschi di Siena, Banco Popolare, and UBI Banca have adopted federal models. Mediobanca is in a category of its own due to its origins as an investment bank. Intesa Sanpaolo and UniCredit manage their corporate and investment banking business through a special division, which includes both the interface with corporate customers and product specialists. The service model is based mainly on the synergy between the network of relationship managers, who interact with companies, and whose task it is to respond to and identify their financial needs, and the product specialists who select, design, and adapt the most suitable instruments for them. In both cases, the coverage network fulfills a number of different functions: 1) management of the complete relationship with the customer corporation under a unified, global approach; 2) provision of a contact point to which the corporation can turn with its financial needs; 3) activation of the product specialists when appropriate. Basically, the territorial network acts as originator, turning as appropriate to the various teams of specialists, who operate within external companies with a high degree of independence. Intesa Sanpaolo has placed these specialist competences in a bank dedicated totally to this area of business, while UniCredit groups its product specialists together in product lines, specific units within the division. 
Monte dei Paschi di Siena, Banco Popolare, and UBI Banca have adopted a similar model but with separation between the coverage and product networks. Coverage is provided by the group's member banks, which retain independence and visibility by reason of their distribution networks. Within these banks, specific business centres are assigned to the provision of coverage for investment banking. On the other hand, product specialist functions are organised within totally dedicated banks. Differences emerge with regard to the activities undertaken by these specialist entities. In the case of Monte dei Paschi di Siena, the specialist bank delivers services to the group, while in that of UBI Banca, the specialist bank both functions as product specialist for the group and supplies coverage in relation to large corporate and institutional customers, which it handles directly. The Banco Popolare specialist organisation is different again, since it also operates in the areas of investment and private banking. This arises from the fact that the customer base consists largely of small and medium-sized enterprises, where the distinction between the entrepreneur and his business is extremely blurred; therefore, the bank has integrated its corporate and family businesses to offer entrepreneur families a single contact, for both the routine and the extraordinary needs arising within the management of their business and private affairs.

As already mentioned, Mediobanca is the Italian bank closest to the US and UK investment bank model. Over time, the frontiers of its operations have been expanded, and simultaneously its organisational model has evolved, to the point where it now comprises three business areas: corporate and investment banking, also including the wholesale banking and financial leasing businesses; principal investing, managing the portfolio of long-term investments in firms and the merchant banking and private equity portfolios; and retail and private banking, comprising consumer credit, retail banking (with the primary aim of acquiring deposits), and private banking. The organisational structure is that of a group, which does not include any specific firms in the CIB area (except for the asset management side of private equity, managed by a separate company), but rather uses teams of specialists. The retail and private banking business areas, on the other hand, are covered by specific companies directly responsible for both coverage and production.

\subsection{Corporate and investment banking business areas}

Exactly which services are included in the corporate and investment banking area depends on the definition of investment banking used 
(Kuhn 1990; Iannotta 2010; Brigham and Ehrhardt 2011; Fleuriet 2008). There is no single, universally accepted criterion for setting the boundaries of this area of operations. Various studies have made a detailed examination of how the relevant services should be identified, but no single view emerges from the literature on the subject. At the two extremes there are one restrictive and one broad definition. The former derives from the historic model of underwriting on the primary market and trading on the secondary market and excludes all the other areas of activities, including advisory services in merger and acquisition processes. The broad definition, on the other hand, reflects the evolution of the business of banks in this sector and includes a varied array of services: as well as underwriting and trading activities, it comprises merchant banking, asset management, advisory services in merger and acquisition or restructuring operations and risk management activities, through to lending. Between these two extremes there are other definitions, which may exclude asset management, lending, risk management or merchant banking, considering them not to be intrinsic to the investment banking business.

According to a broad definition, CIB services can be subdivided into the following business areas (Liaw 2011; Capizzi 2007):

- investment banking in the strict sense

- corporate finance services

- structured finance

- merchant banking

- risk management

Investment banking in the strictest sense relates to access to capital markets through operations in the primary market. The service is based on a process comprising four phases: origination, advisory, arranging, and distribution. In view of the economies of scale that can be generated, secondary market trading is often included in this area of business, although the services are kept separate.

The corporate finance services area covers a combination of various services intended to optimise the financial strategies of customer corporations and has strong advisory connotations. Here again, the process can be subdivided, this time into three phases: origination, advisory, and fund raising. Fund raising refers to the sourcing of the funds needed to complete the operation and often involves the organisation of syndicated loans. Corporate finance services provide support for extraordinary financial operations, relating to the acquisition of 
other companies, or conversely, to corporate sales and restructuring processes.

Structured finance involves the organisation of operations based on cash flows derived from assets or from investment projects separate from the company's core business, handled through special purpose vehicles (SPVs). The process subdivides into four phases: origination, advisory, arranging, and fund raising. Project finance, securitisation, and leveraged finance operations fall within this category.

Merchant banking operations involve the acquisition of equity holdings in non-financial companies by the financial operator. This is not strictly speaking a corporate banking service, since the package is acquired not by a customer but by the bank itself. It can, however, be defined as an asset management service if the funds used do not belong to the bank but are managed under a specific mandate.

In the CIB services, the risk management business area is the most recent and can be subdivided into two segments: the supply of products and services for the management of the risks of corporate customers, and the research and development of risk measurement and management models.

From the operational point of view, the distinction in the above business areas is less clear, since the teams assigned to these services often operate transversely and not just vertically, depending on whether fund raising or advisory services are involved. For example, within an extraordinary financial operation, funding may be handled by the structured finance team, working alongside the team from the corporate finance area.

In terms of the services offered, the sample consists of the top five banking group and Mediobanca, appears to be more uniform. The only exception is UniCredit, which has cut back its merchant banking business to virtually nil. With regard to all the other services, the banks studied declare that they cover all corporate and investment banking services in the broad sense.

However, the importance of each individual area of business within the total volume handled, and the depth of the service offered, vary from bank to bank, depending in particular on the geographical area covered and the clientele served.

In the case of the commercial banks, it is interesting to note the size thresholds into which the business is subdivided, which indicates the orientation towards and importance of relationship banking. Table 8.4 illustrates the situation in 2011. Naturally, the levels of the thresholds and the number of segments depend on the portfolios of companies served. In general, the definition of these is still 
Table 8.4 Segmentation thresholds of banks, in millions of euros, 2011

\begin{tabular}{lccc}
\hline & & \multicolumn{2}{c}{ Corporate } \\
\cline { 3 - 4 } Bank & SME & Mid & Large \\
\hline Intesa Sanpaolo & $€ 2.5-150$ & $€ 150-500$ & $>€ 500$ \\
UniCredit & $€ 3-50$ & $€ 50-250$ & $>€ 250$ \\
Monte dei Paschi di Siena & $€ 0-5$ & $€ 5-200$ & $>€ 200$ \\
Banco Popolare & $€ 0-5$ & $€ 5$ & \\
UBI Banca & $€ 3-15$ & $€ 15-250$ & $>€ 250$ \\
\hline
\end{tabular}

Source: Processing of corporate data (various years).

ongoing; some banks (Intesa Sanpaolo and UniCredit) have revised their categories, while for others the revision in currently underway. Intesa Sanpaolo and UniCredit have the largest, most varied corporate customer portfolios and have proceeded in two stages. First, they excluded small firms from the market of reference by introducing a minimum threshold for access to this type of service, and they established corporate centres, branches specialising in handling relations with corporate clientele. In the second phase, they redistributed the clientele by introducing a distinction between large corporate and corporate customers, setting new quantity thresholds with a higher access threshold and assigning customers to specific coverage facilities: corporate centres and business centres. The customer bases of Monte dei Paschi di Siena, Banco Popolare, and UBI Banca consist largely of SMEs. These banks also initially set an access threshold and redistributed the companies above it, but they have only recently announced that they intend to rationalise their organisation, raising the threshold for access to corporate banking services and reallocating firms amongst the specialist facilities.

Basically, by raising the threshold for access to corporate and investment banking services, Italian banks are creating conditions that will enable them to strengthen the figure of the client manager, through the greater concentration of resources in a more uniform customer portfolio. The client manager is the key figure, since he acts as the contact for the user's needs, facilitating the relationship with the organisation, especially when the service required is complex and a large number of functions have to be involved.

Several significant differences emerge from the breadth and depth of the range of CIB services. Intesa Sanpaolo, UniCredit, and Mediobanca are revealed to be universal banks, capable of providing clientele with assistance in all phases. 
In the case of merger and acquisition operations, market scouting and feasibility studies are carried out in the preliminary phase, moving on to the analytical due diligence procedure and financial structuring and optimisation, through to the negotiation and closing stage.

In structured finance operations, the teams are involved in all phases of the process, from organisation, acting as advisers and arrangers and assisting the project's promoters in the drafting of the business plan, through to the structuring and underwriting stages, with definition of the optimal mix of funding sources.

In securitisation operations, teams are specialised in the management of the entire process structuring phase, from detailed analysis of historic performances and portfolio composition through to complete management of the rating process, which involves the due diligence analysis, preparation of the rating book, selection of the portfolio, negotiation of credit enhancement levels, and the definition of structural and legal characteristics.

In both equity and debt listing operations, teams assist the issuer in all phases of the process: from the design of the structure of the offering in terms of both amount and characteristics, to coordination of the offering and investor relation services both during the process, with organisation of the road shows and, during the after-market phase, with the aim of maximising the value of the issue in the medium-long term.

These operators also cover the role of project manager, organising and coordinating the work of the entire specific desk: from auditors and legal, fiscal, and communications advisers through to professionals specialising in management problems.

With regard to breadth of service, Monte dei Paschi di Siena is in an intermediate position, since it has the know-how necessary to supply a high degree of breadth and depth of service but its relational network is currently less broad and it therefore mainly operates at the domestic level, and rarely as the leader of a syndicate. Banco Popolare and UBI Banca, on the other hand, offer less depth of service, since they have more focused operating capabilities, which means that they are not able to act as project manager but may take part in one or more phases of the process, depending on the type of operation.

In terms of the degree of internationalisation of the offering of corporate and investment banking services, Italian banks operate basically at the domestic level. Although all the banks considered have organisations abroad-varying from highly internationalised positions such as that of UniCredit, which has a network of foreign banks in 22 countries, 
to Monte dei Paschi di Siena, with just a few liaison offices-all the services offered in this sector overwhelmingly target the domestic market. However, during the last few years three banks, UniCredit, Intesa Sanpaolo, and Mediobanca, have launched actions intended to gain them a larger role on the international markets. In the capital markets, they have increasingly taken part in share- and bond-offering projects. In contrast to their leading role on the domestic market, their lower profile internationally has meant that they have operated by acquiring mandates within offering consortia. The operations concerned have involved offerings by foreign issuers and, in some cases, offerings by domestic issuers on foreign markets, such as the Prada initial public offering. Internationalisation appears to be very important in view of the increasingly globalised, interrelated economic context: since a large proportion of corporate and investment banking services concern operations of extraordinary significance for firms, the aid of an international bank can be highly beneficial. This can apply, for example, to the external expansion of a customer corporation through joint venture or acquisition processes, to capital fund-raising operations in the markets considered most attractive, and to sales-for example, to cover generational handovers.

It appears likely that internationalisation will further extend the split at the heart of the Italian banking system: in general terms, it seems that the market will be divided between a small number of institutions capable of supplying the full array of corporate and investment banking services, responding to the opportunities offered by membership of an international network, and the rest of the market, which will be much more limited and will only be able to supply a small selection of advisory services, typical of the merchant banking sector, operating as originator. Intesa Sanpaolo, UniCredit, and Mediobanca can be expected to draw on the experience already acquired to target the large corporate and mid-corporate clientele, especially customers with high potential for international operations; Monte dei Paschi di Siena, Banco Popolare, and UBI Banca seem destined to operate solely on the domestic market, serving smaller-sized corporate customers whose financial needs are less complex or less linked to internationalisation processes.

\section{Notes}

1. A thorough, in-depth analysis of the relationship between small and medium-sized enterprises and the banking system is provided in Caselli (2001). There are many diversities within the category of small and medium-sized enterprises that are worth examining in greater depth. One possible useful 
distinction here is the difference between simple and complex enterprises suggested by Zara (2007): the former have traditional financial behaviours, working mainly with banks on a relationship model, while the financial behaviour of the latter is oriented towards a transaction banking model.

2. The 1936 banking law remained substantially unchanged until the mid 1980s, which saw the start of the process of banking system reform, which led, in August 1993, to the introduction of the new banking law, the Consolidated Law on Banking.

3. The information can be obtained from the answers to the following three questions: 1) during the current year, did the firm want more loans at the prevailing market conditions? 2) If so, during the year did the firm apply unsuccessfully for more credit? 3) If so, would the firm have agreed to pay a slightly higher loan rate to obtain more loans? Firms that replied yes to all three questions were considered to have suffered strong rationing, while positive replies to the first question were viewed as indicating weak rationing. Firms answering yes to the first two questions are defined as suffering from financial constraint. See UniCredit (2009). tab. 9, p. 126.

4. During 1995-2003 (covered by three surveys), the values averaged around $16.0 \%$ for weak rationing, $4.53 \%$ for financial constraints, and $2.8 \%$ for strong rationing. See Brighi (2009), tab. 2.6, p. 95.

5. Substandard loans are loans to customers suffering from temporary difficulties that are likely to be overcome in a reasonably short time. Restructured loans are loans for which a bank, owing to the deterioration in the debtor's financial condition and operating results, accepts changes to the original terms and conditions of loans that caused a loss. Overdue/overdrawn loans are loans that, at the reference date of the report, have been overdue and overdrawn for more than 90 days, secured and unsecured.

6. The market shares of the banks belonging to the main groups fell from 73 per cent in 1996 to 60 per cent in 2005. See Saccomanni (2006) p. 17. During 1996 and 2005, the small banks' market share rose from 24 to 31 per cent. See Gobbi (2007), p. 33. Overall, during the two years after the summer 2007 financial crisis, the five largest groups' share of the corporate lending market fell by more than five percentage points. See Mieli (2009).

7. Operations of this kind include the acquisition by Banca Popolare di Milano of Banca Akros, by Banco Popolare of Banca Aletti, by Banca Intesa first by Lazard Italia and subsequently, through its merger with Sanpaolo, by Banca IMI and by Capitalia (subsequently incorporated into UniCredit) of Medio Credito Centrale. UniCredit founded UniCredit Banca Mobiliare and then proceeded with further changes to its organisation, while Credem established AbaxBank. Acquisitions of specialist merchant banks include, for example, those of Centrobanca by Banca Popolare di Bergamo (UBI Banca) and of MPS Merchant and Ducato Venture by the Monte dei Paschi di Siena group.

8. At the international level, during the last few years there has been a process of acquisition by the large integrated banking groups, for example: Boston has joined the Crédit Suisse group, Morgan Grenfell and Banker's Trust have been acquired by the Deutsche Bank group, Shroder has been taken over by Citigroup, and more recently Bank of America has acquired Merrill Lynch. 
9. The most important foreign players include Rothschild, Morgan Stanley, Deutsche Bank, Goldman Sachs, Lazard, Citi, Credit Suisse, KPMG, BNP Paribas, and Royal Bank of Scotland.

10. This even occurs in the case of groups such as BNP Paribas and Crédit Agricole, which cover the market through their own banking subsidiaries, here Banca Nazionale del Lavoro and CariParma respectively.

11. In the United States, where once there were 17 major investment banks, there now are only 5; as of 2011. Goldman Sachs and Morgan Stanley are the only investment banks to have survived the financial turbulence as independent organisations, and even they have been transformed into bank holding companies, which places them under the surveillance of the Federal Reserve, allowing them to access its system of advances and loans. Bear Stearns was taken over by JPMorgan Chase \& Co. at the end of May 2008, while Merrill Lynch was acquired by Bank of America, in effect from the first of January 2009. In September 2008 Lehman Brothers declared itself bankrupt and its European and Asian businesses were taken over by Nomura, and its North American operations by Barclays.

12. Compared to the banks of other countries, which are more dependent on wholesale funding, the Italian banking system enjoys a large supply of retail funds that are relatively immune to market volatility. See Banca d'Italia (2011a). 